\title{
Fostering research skills in undergraduate medical students through Mentored Student Projects: Example from an Indian medical school
}

\author{
Devi V, ${ }^{1}$ Abraham RR, ${ }^{2}$ Adiga $A,{ }^{3}$ Ramnarayan $\mathrm{K},{ }^{4}$ Kamath $\mathrm{A}^{5}$
}

${ }^{1}$ Department of Pharmacology, ${ }^{2}$ Department of Physiology, ${ }^{4}$ Department of Pathology, Melaka Manipal Medical College, Manipal University, Manipal, India.

${ }^{3}$ Department of Pharmacology, ${ }^{5}$ Department of Community Medicine, Kasturba Medical College, Manipal University, Manipal, India.

\section{Corresponding author}

Dr. Vasudha Devi

Department of Pharmacology

Melaka Manipal Medical College

Karnataka, India.

email: vasudha_manipal@yahoo.co.in

Kathmandu Univ Med J 2010;8(31):294-8

\begin{abstract}
Background

Healthcare decision-making is largely reliant on evidence-based medicine; building skills in scientific reasoning and thinking among medical students becomes an important part of medical education. Medical students in India have no formal path to becoming physicians, scientists or academicians.
\end{abstract}

\section{Objectives}

This study examines students' perceptions regarding research skills improvement after participating in the Mentored Student Project programme at Melaka Manipal Medical College, Manipal Campus, India. Additionally, this paper describes the initiatives taken for the continual improvement of the Mentored Student Project programme based on faculty and student perspectives.

\section{Methods}

At Melaka Manipal Medical College, Mentored Student Project was implemented in the curriculum during second year of Bachelor of Medicine and Bachelor of Surgery programme with the intention of developing research skills essential to the career development of medical students. The study design was cross-sectional. To inculcate the spirit of team work students were grouped ( $n=3$ to 5 ) and each group was asked to select a research project. The students' research projects were guided by their mentors.

A questionnaire (Likert's five point scale) on students' perceptions regarding improvement in research skills after undertaking projects and guidance received from the mentor was administered to medical students after they had completed their Mentored Student Project. The responses of students were summarised using percentages. The median grade with inter-quartile range was reported for each item in the questionnaire. The median grade for all the items related to perceptions regarding improvement in research skills was 4 which reflected that the majority of the students felt that Mentored Student Project had improved their research skills. The problems encountered by the students during Mentored Student Project were related to time management for the Mentored Student Project and mentors.

\section{Results}

This study shows that students acknowledged that their research skills were improved after participating in the Mentored Student Project programme.

\section{Conclusions}

The Mentored Student Project programme was successful in fostering positive attitudes among medical students towards scientific research. The present study also provides scope for further improvement of the Mentored Student Project programme based on students' and faculty perspectives.

\section{Key Words}

curriculum, , medical students, mentored student projects, methodology, research skills 


\section{INTRODUCTION}

At present, healthcare decision-making is largely reliant on evidence-based medicine and understanding and using scientific methods has become an important component of the medical profession. ${ }^{1}$ It is essential to inculcate critical thinking and reasoning skills, and to develop a positive attitude among medical students towards scientific research from the beginning of their medical career. ${ }^{2}$ In this context, research projects not only fosters analytical thinking and self-directed learning skills among students, but also improves their oral and written communication skills. Furthermore, these projects play a role in producing physicians who are better equipped to evaluate and apply new knowledge to their profession..$^{3-7}$

Currently, medical students in India have limited opportunities to participate in research. Though shortterm scholarships such as the Indian Council of Medical Research (ICMR) and Kishore Vaigyanik Protsahan Yojana (KVPY) provide research opportunities, there is no formal path for medical students in India to become physicians, scientists or academicians. ${ }^{8}$

Realising the needs of medical students, we implemented the Mentored Student Project (MSP) programme in 2007 for the September 2006 batch students of our institution. In this paper, we make an attempt to report students' perceptions regarding research skills improvement after participating in the MSP programme. Additionally, the present study describes the initiatives taken in our medical school for the improvement of the MSP programme based on faculty and student perspectives.

\section{METHODS}

Our medical school offers a medical education programme at two campuses. There are two admission intakes per year; one in March and another in September. Students admitted are initially placed in India (Phase I of the programme) and after successfully completing two and a half years of pre-clinical training, they return to Malaysia for the clinical training (Phase II of the programme). Phase I of the programme is divided into 3 stages, Stage I, Stage IIa and Stage IIb. Students study anatomy, physiology and biochemistry in Stage I. Pathology, pharmacology, microbiology and forensic medicine are taught in Stage IIa. In Stage IIb, clinical subjects are taught.

The MSP programme was implemented in the curriculum with the intention of developing research skills essential to the career development of medical students. In the MSP, students were required to undertake a project involving an in-depth study of an area of their interest; to write a scholarly report; and to present their work as a poster presentation over a period of 6 months. It was mandatory that the study should deal with a well-defined problem or be designed to test a particular hypothesis no matter whether the project is conducted in the laboratory, clinic or in the field.

Keeping in mind the cultural background and specific needs of international students, our medical school took the initiative to develop a mentorship scheme, whereby mentors (faculty who are basic scientists) are required to supervise the academic progress of students who are assigned to them. The mentors not only encourage, guide and advise their mentees in curricular and extracurricular activities, but also guide them in MSP during their Phase I Stage IIa. Research shows that guidance provided by the mentor during project work does improve student involvement significantly. ${ }^{9}$ Over the course of MSP, mentors will have regular contact with the students. Mentors must review and approve the project proposal and final report. Mentors will guide the students during all phases of the project, from research topic selection; ethical consideration; writing the proposal; data collection; analysis and interpretation; writing up the final report and designing poster for poster presentation.

Science and research are rapidly evolving from being separate disciplines to a highly collaborative and interdisciplinary activity. ${ }^{10}$ Research training for undergraduate medical students should also inculcate the spirit of team work. To achieve this, students were grouped ( $n=3$ to 5 ) and each group was asked to select a research project in the form of a library study, laboratory research, record study, case study, field project or some other activity. We encouraged students to select the research topic themselves and thus, students had a feeling of project ownership which is reported to be an essential feature of ideal undergraduate research. ${ }^{11}$

To examine the students' perceptions regarding research skills improvement after participating in the MSP, a questionnaire (Likert's five point scale) was developed after an extensive literature review. The questionnaire had 16 items related to research skills gained by undertaking projects and guidance received from the mentor. Students were also required to indicate whether their previous research experience was extensive, limited or nil. Content validity of the questionnaire was determined by experts in medical education. Reliability of the questionnaire was determined by Cronbach's alpha. The questionnaire used in the study was completely anonymous. The present study was approved by the Institutional Review Board of MMMC. Before administering the questionnaire, purpose of the study was explained to the students and informed consent was taken. 
The questionnaire (Table 1) was administered to September 2007 batch students after they had completed their MSP. There were 36 mentored student projects guided by a total of 16 mentors.

Students were requested to indicate their responses in the questionnaire. The respondents were also requested to provide informal comments, if any.

Mentors were also asked to comment informally regarding the weaknesses of the present MSP programme so it can be modified and made more effective in the future.

The test-retest reliability of the questionnaire was assessed and Cronbach's alpha at test was found to be 0.777 and 0.869 at retest, indicating good internal consistency. The responses of students and mentors were summarized using percentages. The median grade with inter-quartile range (IQR) was reported for each item in the questionnaire Comparison of overall research skills gained based on previous research experience of students was done using Chi-Square test. Statistical analysis was performed using SPSS Version 11.5.

\section{RESULTS}

A total of 113 students participated in the study. It was encouraging to find a response rate of $97 \%$. The median grade for all the items related to perceptions regarding improvement in research skills was 4 which means that majority of the students felt that MSP had increased their research skills (Table 1). Thirty five students out of 113 reported that they had no previous research experience, while the remaining students had limited research experience.

Students reported that their research studies were based on a questionnaire survey among students and faculty (59\%), retrospective data from medical records (9\%), literature search (9\%), laboratory research (8\%), and epidemiology or public health (15\%). All projects using questionnaire surveys were found to be related to health issues. These surveys tested knowledge (17\%), knowledge and practice (25\%), knowledge and attitude (14\%), knowledge, attitude and practice (3\%) among students and faculty. The past research experience of the students had no bearing on most of the skills for research except critical evaluation of literature. 27 out of the 32 with no previous research experience had no preference to critical evaluation of literature, while 39 out of 81 among the ones with little experience disagreed with it $(p=0.003)$. It was observed that the type of project was not significantly related to the improvement in overall skills and problems encountered. $15 \%$ of the students felt that MSP was time consuming and that they felt difficulty in balancing other academic activities. Students (5\%) felt that time allotted for the MSP was too short. 6\% of the students reported problems pertaining to mentors (high expectations of the mentors). Other problems encountered were found to be related to selection of appropriate title, statistical methods and finance.

It was encouraging to find that $80 \%$ of the respondents received appropriate guidance from their mentors. $1 \%$ of students felt that MSP was very stressful because of mentors' high expectations. 10\% of students felt that MSP had improved their relationship with their mentors.

A further $10 \%$ of students felt that through MSP, they could work in a research field which they were interested in. 9\% of students opined that MSP is the best way to improve research skills and it serves as a platform for further research. 20\% of students perceived MSP as a rewarding experience. $5 \%$ of students felt that the experience gained through MSP have taught them to balance various academic activities.

$61 \%$ of students agreed that MSP should be a mandatory requirement for the completion of the MBBS programme, whereas $12 \%$ did not agree for the same. $10 \%$ percent of the students opined that MSP should be evaluated and marks obtained should be added to the internal assessment for the final summative examination of Phase I Stage IIa. Students (64\%) also felt that they could have done MSP in a better way if they were given proper orientation in the form of a workshop. $10 \%$ of students considered Phase I Stage IIb as the best time for MSP as they would be able to link basic science with medicine. $10 \%$ of students felt that the MSP should be a clinically related topic or a laboratory based research and not a mere literature review. It was heartening to note that $5 \%$ of students opining that the publication of MSP work be made compulsory.

\section{DISCUSSION}

In Indian medical schools, avenues for research in undergraduate curriculum are minimal. This paper emphasizes the scope of student projects in fostering research skills in undergraduate medical students. The MSP program at MMMC is intended to inculcate an attitude in students to involve in research and also to create an awareness regarding the relevance of research in their future profession. We presume that the experiences gained through MSP will help students to understand and make use of evidence based medicine in their future professional career.

From this study, 61\% of students felt that MSP should be a mandatory requirement for the completion of the MBBS degree. This suggests that the non-funded MSP 
Table 1. Median [with inter-quartile range (IQR)] for perception of

\section{improvement in research skills by students after MSP}

\begin{tabular}{lcc}
\multicolumn{1}{c}{ Items } & Median \\
To write protocol for scientific study & 4 & $(3,4)$ \\
To formulate goal/ objectives & 4 & $(3,4)$ \\
To conduct literature search & 4 & $(3,4)$ \\
Independently administer the intervention & 4 \\
To collect data & 4 \\
Critically evaluate literature & 4 \\
Evaluate the strengths and weakness of my own study & 4 \\
Write project report & 4 \\
Use computers & 4 \\
Use statistical software packages & 4 \\
To present scientific data appropriately & 4 \\
To share thoughts and opinions with peer & $4,4)$ \\
To work in a group & 4
\end{tabular}

programme was successful in fostering a positive attitude towards scientific research. The positive response and research skills gained, may contribute to the development of responsible conduct of research in an academic environment. ${ }^{13}$ Though the median grade for all the items related to improvement in research skills was 4 on the Likert's scale (Table 1), most of the faculty felt that students' performance would improve considerably more if they underwent short term training in research methodologies including biostatistics and ethics

As the first stepping stone among the multitude of reforms suggested by the students and faculty, the medical school has decided to implement workshops on research methodologies at the commencement of Phase I and Stage IIa. Furthermore, to streamline the MSP programme, a coordination committee with the Dean as the chairperson and two faculty members, was formed. The committee has been successful in formulating guidelines for MSP, which is published in the student brochure. It has also been decided that students will be given an MSP checklist which focuses on the tasks to be accomplished within the given time frame.

It is reported that when a student gets an opportunity to conduct research, he/she should be provided an equal opportunity to present and discuss the work. ${ }^{12}$ The scientific communication has been recognized as a crucial step in the development of a young scientist. ${ }^{13}$ In this context, our medical school was successful in providing an opportunity for scientific communication by arranging poster presentation. The faculty and students had the unique opportunity to reflect, appreciate and provide suggestions for further improvement. The faculty felt that students should be encouraged to present their research work in conferences and to publish in peer reviewed journals.

In research, we often experience the trial and error processes involved with proposing and testing hypotheses. Students may not experience this entity by just doing a literature search. Our medical school has decided to encourage more and more community based and hospital based research activities than a research activity involving just a literature search.

The concept of 'research' for undergraduate level medical students has a bright future only if there is commitment and backing from the faculty. ${ }^{12}$ Though $62 \%$ of the students agreed that they received appropriate guidance from their mentor, $12 \%$ of students did not agree, which is a matter of concern. In this regard, the MSP coordination committee has requested that mentors report the research activities of their mentees, every 2 months. It is believed that the majority of medical students are examination oriented and are quite content in following the prescribed syllabi to the extent that involving themselves in other academic tasks is perceived to be cumbersome and time consuming. In this context, it was encouraging to note that, in this study, 9\% of the students opined that MSP is the best way to improve their research skills and that it serves as a platform for future research. $5 \%$ of students also wanted the compulsory publication of MSP. Therefore, in the present study, 5-9\% of students were found to be knowledge hungry and may be really interested in future research. Identifying and nurturing these students through special research programmes is crucial for the generation of new knowledge.

The present study did not explore students' perspectives regarding research skills before they undertook the MSP programme. Moreover, the study is based on students' perceptions and not on the actual research skills gained 
through MSP. The study did not compare the test and control groups. The authors are planning to research on more objective measures of the MSP programme.

\section{CONCLUSIONS}

To conclude, the present study revealed that the MSP programme not only increased students' research skills as evident from their perceptions but was also successful in fostering a positive attitude towards scientific research. The present study also provided scope for further refinement of the MSP programme based on students' and faculty perspectives.

\section{REFERENCES}

1. Bornstein BH, Emler AC: Rationality in medical decision making: a review of the literature on doctors' decisionmaking biases. J Eval Clin Pract 2001;7:97-107.

2. Ghali WA, Saitz R, Eskew AH, Gupta M, Quan H, Hershman WY: Successful teaching in evidence-based medicine. Med Educ 2000;34:18-22.

3. Kanter SL, Wimmers PF, Levine AS. In-depth learning: One school's initiatives to foster integration of ethics, values, and the human dimensions of medicine. Acad Med 2007;82:405-9.

4. Schor NF, Troen P, Kanter SL, Levine AS. The Scholarly Project Initiative: Introducing scholarship in medicine through a longitudinal, mentored curricular programme. Acad Med 2005;80:824-31.

5. Parsonnet J, Gruppuso PA, Kanter SL, Boninger M. Required vs. elective research and in-depth scholarship programmes in the medical student curriculum. Acad Med 2010;85:405-8.

6. Green EP, Borkan JM, Pross SH, Adler SR, Nothnagle M, Parsonnet J, et al. Encouraging scholarship: Medical school programmes to promote student inquiry beyond the traditional medical curriculum. Acad Med 2010;85:409-18.

7. Bierer SB, Chen HC. How to measure success: The impact of scholarly concentrations on students-A literature review. Acad Med 2010;85:438-52.

8. Dangayach NS, Kulkarni UP, Panchabhai TS: Mentoring medical student research through studentships and fellowships: Reflections from India. J Postgrad Med 2009;55:152-3.

9. Carson S. A new paradigm for mentored undergraduate research in molecular microbiology. CBE Life Sci Educ 2007;6:343-9.

10. McGee R, DeLong MJ. Collaborative co-mentored dissertations spanning institutions: influence on student development. CBE Life Sci Educ 2007;6:119-31.

11. Lopatto D. The essential features of undergraduate research. Council Undergraduate Res. Quart 2003;23:139-42.

12. Mastroianni AC, Kahn JP. The importance of expanding current training in the responsible conduct of research. Acad Med 1998;73:1249-54.

13. Camba R. Millennium essay: start making sense. Nature 2000;406:461. 